\title{
Streptomyces felleus YJ1: Potential Biocontrol Agents Against the Sclerotinia Stem Rot (Sclerotinia sclerotiorum) of Oilseed Rape
}

\author{
Guanglong Cheng ${ }^{1}$, Yun Huang ${ }^{1}$, Hui Yang ${ }^{1} \&$ Fan Liu ${ }^{2}$ \\ ${ }^{1}$ Department of plant Pathology, Sichuan Agricultural University, Wen'jiang 611130, Chengdu, Sichuan \\ Province, China \\ ${ }^{2}$ Guangxi Botanical Garden of Medicinal Plants, Nan'ning, Guangxi Province, China \\ Correspondence: Yun Huang, Department of plant Pathology, Sichuan Agricultural University, Wen'jiang \\ 611130, Chengdu, Sichuan Province, China. E-mail: 5787huangyun@sina.com.cn
}

Received: October 9, 2013 Accepted: November 28, 2013 Online Published: March 15, 2014

doi:10.5539/jas.v6n4p91 URL: http://dx.doi.org/10.5539/jas.v6n4p91

\begin{abstract}
In order to explore the biocontrol potential of Streptomyces felleus YJ1 to sclerotinia stem rot of oilseed rape, we evaluated the effects of YJ1 as antagonistic strain on Sclerotinia sclerotiorum, including germination and formation of sclerotia, ascospore germination, mycelial growth and YJ1 colonization ability. We found the fermentation filtrate of YJ1 could inhibit sclerotia and ascospore germination and mycelial growth. In dual culture the inhibition zone diameter of YJ1 against $S$. sclerotiorum was $11.0 \mathrm{~mm}$, and the inhibition rate reached to $80.26 \%$. The ascospores germination was also significantly inhibited by YJ1 fermentation filtrate. In addition, YJ1 could colonize stably in rhizosphere and roots of rape. Otherwise, in the greenhouse we found the lesion would become smaller and slighter if the inoculated leaves were pretreated with YJ1 fermentation liquid. Therefore, our results strongly suggested that YJ1 was a promising biocontrol agent for control of oilseed rape sclerotinia stem rot.
\end{abstract}

Keywords: Streptomyces felleus, Sclerotinia sclerotiorum, antagonistic effect, colonization

\section{Introduction}

Sclerotinia stem rot of oilseed rape caused by the fungus Sclerotinia sclerotiorum (Lib.) de Bary is a widespread soil-borne plant disease (Yan et al., 2005). The fungus is capable of infecting a wide variety of plant species including soybean, bean, pea, lettuce, tomato, sunflower, rape and many other economically important crops (Hegedus \& Rimmer, 2005; Fróes et al., 2012). Oilseed rape (Brassica napus L.) is the major oil crop in China. In recent years, S. sclerotiorum has an increasing threat to oilseed rape cultivation and become a potentially damaging disease. Sclerotinia stem rot can reduce the yield of oilseed rape from $15 \%$ to $60 \%$ (Subbarao, 1998). Due to its wide host-range, effective reproduction and sclerotia which can survive in soil for up to four years without hosts or favorable condition, it is very difficult to control $S$. sclerotiorum (Bae \& Knudsen, 2007).

Many strategies were applied to control the sclerotinia stem rot such as crop rotation and fungicides (Mueller, et al., 2001). However, using crop rotation is unpractical due to the persistence of sclerotia in the soil for long periods (Demoz \& Korsten, 2006). The use of fungicides has adverse effects on non-target organisms, and fungicides even lead to the selection of resistant populations (Huang, Bremer, Hynes, \& Erickson, 2000). Therefore, biological control of sclerotinia diseases was interested as an acting substitute to other controlling methods. Biocontrol via antagonists such as Bacillus, Pseudomonas and mycoparasites Trichoderma spp. against the S. sclerotiorum was reported previously (Fernando et al., 2007; Abdullah, Ali, \& Suleman, 2008). Some actinomycetes (mainly Streptomyces) have been also reported for the control of $S$. sclerotiorum, because these filamentous bacteria produce a wide spectrum of antibiotics as secondary metabolites and different types of enzymes, like chitins, cellulose, peptidase, glucose polymerase, glucanases etc. (Adams \& Ayers, 1979). Many secondary metabolites or different enzymes exhibited strong antagonism against the fungal pathogens (Clardy, Fischback, \& Walsh, 2006; Yuan, \& Crawford, 1995). It exhibited a great application potential.

Recently, we isolated the actinomycetes YJ1 from branches of Ginkgo, and the strain was identified as Streptomyces felleus on basis of morphological, physiological and biochemical characteristics, and the analysis of 16S rDNA sequence (Yao, 2010). In this study, we investigated the antagonistic effects of YJ1 against $S$. 
sclerotiorum and the colonization of YJ1 in the rhizosphere soil and roots of oilseed rape. This is helpful for us to have a fully understanding of the potential of YJ1 for biocontrol of sclerotinia stem rot of oilseed rape caused by $S$. sclerotiorum.

\section{Materials and Methods}

\subsection{Strains, Culture Conditions}

Streptomyces felleus YJ1 was maintained on Gause's medium No.1. Gause's liquid medium and millet liquid medium (including millet $10.0 \mathrm{~g}$, glucose $10.0 \mathrm{~g}$, peptone $3.0 \mathrm{~g}, \mathrm{NaCl} 2.0 \mathrm{~g}, \mathrm{CaCO}_{3} 2.0 \mathrm{~g}$, distilled water $1000 \mathrm{~mL}$, $\mathrm{pH}$ 7.2-7.4) were used for cultivating YJ1. Sclerotinia sclerotiorum was isolated from the sclerotia in the stem of rape from Wenjiang, China and maintained on Potato Dextrose Agar (PDA). YJ1 and S. sclerotiorum were stored at $4^{\circ} \mathrm{C}$ until required.

\subsection{Preparation of Fermentation Filtrate}

The strain YJ1 was cultivated for 4 days at $28^{\circ} \mathrm{C}$ on Gause's medium No.1. The mycelium discs were put into sterile medium in $250 \mathrm{~mL}$ flasks. The flasks were incubated in the dark at $28^{\circ} \mathrm{C}$ on a rotary shaker at $160 \mathrm{r}$. $\min ^{-1}$ for 7 days. The cultures (fermentation broth of $\mathrm{YJ} 1$ ) were centrifuged $\left(8000 \mathrm{r}\right.$. $\left.\min ^{-1}, 4^{\circ} \mathrm{C}\right)$ for 15 minutes to separate the supernatants. The supernatants were sterilized through $0.22 \mathrm{~mm}$ bacterial filter and stored at $4^{\circ} \mathrm{C}$ until required.

\subsection{Antagonism of YJ1 Against S. sclerotiorum}

\subsubsection{Dual Culture Assay}

The mycelial plugs (5 mm diameter) of YJ1 and S. sclerotiorum were placed on the same dish. The $S$. sclerotiorum were placed in the center of the dish and YJ1 were placed at $2.5 \mathrm{~cm}$ of the center inocula. The dishes were incubated at $28^{\circ} \mathrm{C}$ for 3 days. The inhibition zone was measured as the distance between YJ1 and S. sclerotiorum after 5 days. The experiments were repeated 3 times.

\subsubsection{Antibiotic Activity Assay}

Briefly, $1 \mathrm{~mL}$ sterile fermentation filtrate mixed with $9 \mathrm{~mL}$ melted PDA medium was replaced on a dish and $10 \mathrm{~mL}$ PDA medium was used as control. The experiments were repeated three times. And the dishes were incubated for 3 days at $28^{\circ} \mathrm{C}$. Then, colony diameter was measured. The dishes were maintained at $28^{\circ} \mathrm{C}$ for a long time to observe the production of sclerotia.

\subsubsection{Sclerotia Germination Test}

10 sclerotia were selected to sterilize according to previous method. The sterile fermentation filtrate of YJ1 was used for soaking sclerotia for one hour, and sterile water was used as control. Next, the sclerotia were removed on PDA medium. After the dishes were incubated at $28^{\circ} \mathrm{C}$ for 2 days, we measured the germination of sclerotia every 24 hours. The experiments were repeated 3 times.

20 sclerotia were selected to sterilize. The initial sterile fermentation filtrate of YJ1 at a ratio of 5 to 1 and 20 to 1 were used for soaking sclerotia for one hour, and sterile water was used as control. Next, these treatment sclerotia were buried in sterile sands. The favorable moisture was kept. Assessments were started the following spring when sclerotia germinate to form apothecia.

\subsubsection{Ascospores Germination Test}

The ascospores of $S$. sclerotiorum were collected to prepare the spore suspension $\left(2 \times 10^{7} \mathrm{cfu} / \mathrm{mL}\right)$. The spore suspension was mixed with sterile fermentation filtrate of $\mathrm{YJ} 1$ to dilute 5 times and 20 times respectively. We also used sterile water as control. The mixtures were dropped on the glass slides and incubated at room temperature. The germination of ascospores was checked by using microscope after 24 hours. The experiments were repeated 3 times.

\subsection{YJ1 Colonization}

\subsubsection{Streptomycin-Resistant marker Strains}

The strain YJ1 was transferred to Gause's medium No.1 which was added $20 \mu \mathrm{g} / \mathrm{mL}$ streptomycin, and gradually with increasing streptomycin concentration, such that at the maximum concentration used $(500 \mu \mathrm{g} / \mathrm{mL})$. Each time the concentration was increased by $20 \mu \mathrm{g} / \mathrm{mL}$. Then the mutation frequency, the physiological characteristics of the mutant strain and its inhibition effects against $S$. sclerotiorum were checked. Finally, the mutant strains were incubated in the flasks that contained Gause liquid medium added with $500 \mu \mathrm{g} / \mathrm{mL}$ streptomycin. The flasks were 
put in the dark at $28^{\circ} \mathrm{C}$ on a rotary shaker at $180 \mathrm{r}$. $\min ^{-1}$ for 7 days. The bacteria concentration was adjusted to $2.5 \times 10^{7} \mathrm{cfu} / \mathrm{mL}$. The bacterial suspension was stored at $4^{\circ} \mathrm{C}$ until required.

\subsubsection{Determination of Colonization}

The oilseed rapes (Mianyou 16) were sown in pots in the greenhouse. When the plants had four leaves, we inoculated YJ1 by applying a soil drench with $10 \mathrm{~mL}$ YJ1 suspension. After 15 days, the roots and rhizosphere soil of rape were collected to separate streptomycin-resistant marker strains. We collected once per 15 days. Next, we made the determination of colonization in the rhizosphere or roots.

\subsection{Effects of YJ1 on Symptom Development}

When the oilseed rapes had seven leaves, the fermentation liquid of YJ1 was sprayed to the leaves surface. The control was sprayed with distilled water. Then the leaves were inoculated with $S$. sclerotiorum mycelium discs $(0.5$ $\mathrm{cm}$ diameter), and kept moist for 24 hours. The size of lesions was measured after 3 days. The experiments were repeated 3 times.

\section{Results}

\subsection{Antagonism of YJ1 Against S. sclerotiorum}

\subsubsection{Inhibitory Effect of YJ1 on S. sclerotiorum Mycelial Growth}

First, we detected the inhibition zone diameters at ten days. It was about $11.0 \mathrm{~mm}$. This indicated that YJ1 had obvious antagonism against $S$. sclerotiorum mycelial growth (Figure 1). Next, the mycelial morphology was observed in microscopic exams. The normal mycelia of $S$. sclerotiorum are thick and have many septation, and the hyphal front is straight and apex obtuse. While $S$. sclerotiorum grown in the same dish together with YJ1, $S$. sclerotiorum mycelia were affected greatly. They were finer. The mycelia interior appeared many small bubbles and septation became little compared to control. The mycelium front was atrophied (Figure 2). Otherwise, we found that the diameter of $S$. sclerotiorum colony was smaller than control. The inhibitory rate of mycelia growth reached to $80.28 \%$.

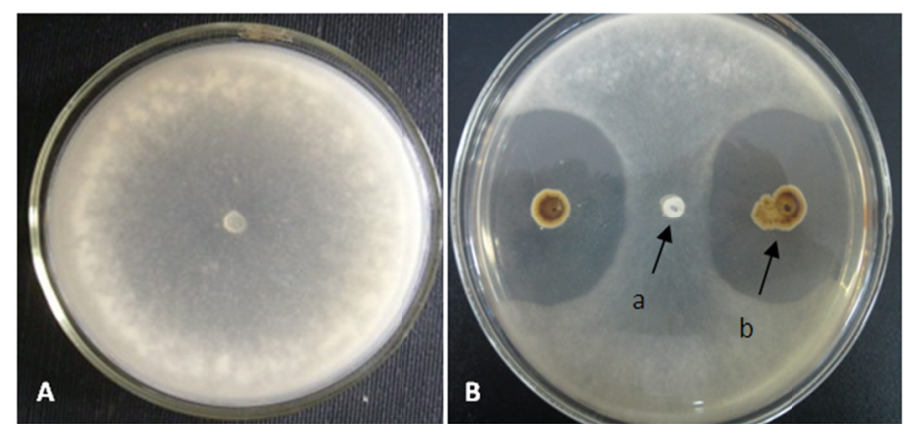

Figure 1. Inhibition effects of strain YJ1 on S. sclerotiorum

A: Control; B: Inhibitory effect of YJ1 on mycelia; a: S. sclerotiorum; b: actinomycetes YJ1.

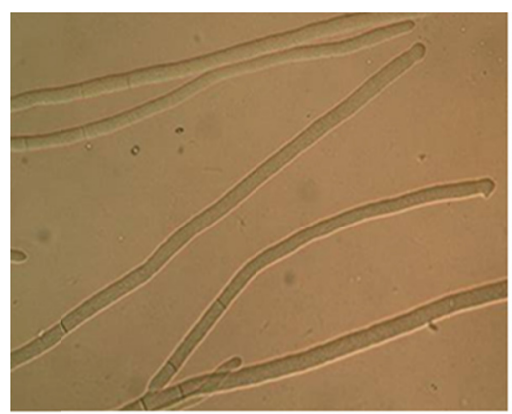

A

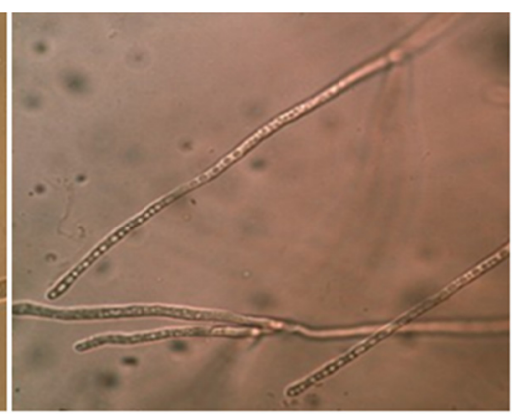

B

Figure 2. Microexamination of depressant effects on mycelia of Sclerotinia sclerotiorum treated by YJ1

A: Normal mycelia; B: Mycelia treated by YJ1. 


\subsubsection{Inhibitory Effects of YJ1 on Sclerotia Formation}

We continued to detect the effect of YJ1 on S. sclerotiorum sclerotia formation. The results showed that the control began to produce sclerotia at five day, however, in the treatment group the sclerotia forming at least need seven days. Otherwise, we found in the Antibiotic Activity Assay the number of sclerotia were little than control at any different days. It indicated that the formation of sclerotia was greatly restrained by YJ1 (Table 1.). The inhibition rate of sclerotia formation was still $79.05 \%$ at 11 day. Thus, YJ1 could not only restrain the number of sclerotia production, but also delay the formation time.

Table 1. Inhibition effects of YJ1 on the quantity of sclerotium production

\begin{tabular}{cccc}
\hline \multirow{2}{*}{ Time } & & \multicolumn{2}{c}{ Treatment } \\
\cline { 3 - 4 } & & Control & YJ1 \\
\hline \multirow{2}{*}{$5 \mathrm{~d}$} & Sclerotium number (Av.) & $7.7 \mathrm{a}$ & $0.0 \mathrm{~b}$ \\
& Inhibition rate (\%) & - & 100 \\
\multirow{2}{*}{$7 \mathrm{~d}$} & Sclerotium number (Av.) & $19.0 \mathrm{a}$ & $3.3 \mathrm{~b}$ \\
& Inhibition rate (\%) & - & 82.63 \\
\multirow{2}{*}{$9 \mathrm{~d}$} & Sclerotium number (Av.) & $23.7 \mathrm{a}$ & $4.7 \mathrm{~b}$ \\
& Inhibition rate (\%) & - & 80.17 \\
\multirow{2}{*}{$11 \mathrm{~d}$} & Sclerotium number (Av.) & $25.3 \mathrm{a}$ & $5.3 \mathrm{~b}$ \\
& Inhibition rate (\%) & - & 79.05 \\
\hline
\end{tabular}

Note: The values in the table were the average of three replicates. Different letters in the same row represent significant differences $(\mathrm{P}<0.01)$.

\subsubsection{Inhibition Effects of YJ1 on Sclerotia Germination}

The sterile fermentation filtrate of YJ1 was used for soaking sclerotia. Then the sclerotia were put on the PDA medium. After 48, 72 and 120 hours, we found the sclerotia germination rates were always lower than control. However, after 168 hours all sclerotia germinated (Table 2). The results showed that sclerotia germination could be restrained by YJ1, but the inhibitory effects only maintained a short time. Eventually, the germination of sclerotia was not affected by YJ1 fermentation filtrate.

Otherwise, the sclerotia germination and apothecium production could be affected by different concentration of YJ1 fermentation filtrate. As seen in Table 3, the initial fermentation filtrate had extreme effects. The sclerotia germination rate was about $10 \%$, while the control was $100 \%$. The inhibition rate of apothecium formation was the highest in the initial fermentation filtrate. But with the filtrate concentration reducing, the inhibition rate decreased obviously.

Table 2. Effects of YJ1 on sclerotia germination

\begin{tabular}{ccccc}
\hline Treatment & $\begin{array}{c}48 \mathrm{~h} \\
\text { Germination } \\
\text { rate (\%) }\end{array}$ & $\begin{array}{c}72 \mathrm{~h} \\
\text { Germination } \\
\text { rate (\%) }\end{array}$ & $\begin{array}{c}120 \mathrm{~h} \\
\text { Germination } \\
\text { rate (\%) }\end{array}$ & $\begin{array}{c}168 \mathrm{~h} \\
\text { Germination } \\
\text { rate (\%) }\end{array}$ \\
\hline Control & $26.67 \mathrm{a}$ & $76.67 \mathrm{a}$ & $100 \mathrm{a}$ & $100 \mathrm{a}$ \\
YJ1 & $20.00 \mathrm{~b}$ & $43.33 \mathrm{~b}$ & $86.67 \mathrm{~b}$ & $100 \mathrm{a}$
\end{tabular}

Note: The values in the table were the average of three replicates. Different letters in the same column represent significant differences $(\mathrm{P}<0.01)$. 
Table 3. Inhibition effects of YJ1 on sclerotia germination and apothecium formation

\begin{tabular}{ccccc}
\hline Treatment & $\begin{array}{c}\text { Sclerotia } \\
\text { number }\end{array}$ & $\begin{array}{c}\text { Germination } \\
\text { number }\end{array}$ & $\begin{array}{c}\text { Germination rate } \\
\text { (\%) }\end{array}$ & $\begin{array}{c}\text { Inhibition rate } \\
(\%)\end{array}$ \\
\hline Control & 20 & 20 & $100 \mathrm{a}$ & $0.00 \mathrm{~d}$ \\
YJ1(1) & 20 & 2 & $10.00 \mathrm{~d}$ & $90.00 \mathrm{a}$ \\
YJ1(2) & 20 & 5 & $25.00 \mathrm{c}$ & $75.00 \mathrm{~b}$ \\
YJ1(3) & 20 & 15 & $75.00 \mathrm{~b}$ & $25.00 \mathrm{c}$ \\
\hline
\end{tabular}

Note: (1) Initial sterile fermentation filtrate of YJ1; (2) Initial sterile fermentation filtrate diluted to 5 times; (3) Initial sterile fermentation filtrate diluted to 20 times. And different letters in the same column represent significant differences $(\mathrm{P}<0.01)$.

\subsubsection{Effects of YJ1 on Ascospore Germination}

As seen in Table 4, the germination of ascospore was obviously restricted by the YJ1 fermentation filtrate. In the treatment group the ascospore germination rate was only $4.05 \%$, however, the control was $94.44 \%$. With the concentration of fermentation filtrate reducing, the inhibitory effect decreased. When the fermentation filtrate was diluted to 10 times, the germination rate of ascospores was $32.58 \%$. It was still lower compared to control. Otherwise, the morphology of ascospores was checked by microscope. We found the front of germ tube was atrophied and tapering when the ascospores were treated with YJ1 fermentation filtrate. They were different from untreated ascospores (Figure 3).

Table 4. The germination rate of ascospores pretreated with the fermentation filtrate of YJ1

\begin{tabular}{cccc}
\hline Treatment & $\begin{array}{c}\text { Initial filtrate } \\
\text { Germination rate } \\
(\%)\end{array}$ & $\begin{array}{c}5 \text { times dilution } \\
\text { Germination rate } \\
(\%)\end{array}$ & $\begin{array}{c}10 \text { times dilution } \\
\text { Germination rate } \\
(\%)\end{array}$ \\
\hline Control & $94.44 \mathrm{a}$ & $94.21 \mathrm{a}$ & $96.36 \mathrm{a}$ \\
YJ1 & $4.05 \mathrm{~b}$ & $24.76 \mathrm{~b}$ & $32.58 \mathrm{~b}$
\end{tabular}

Note: The values in the table were the average of three replicates. Different letters in the same column represent significant differences $(\mathrm{P}<0.01)$.

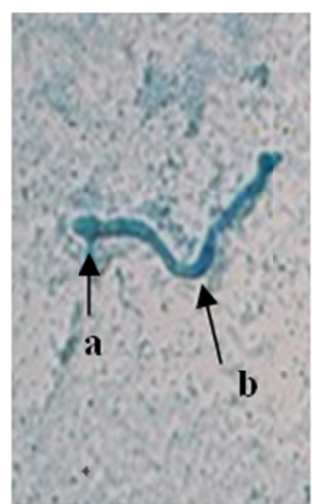

A

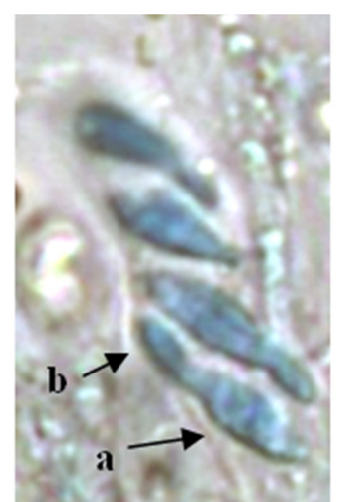

B

Figure 3 Effects of the sterile fermentation liquid of YJ1 on the asporous germination

A: Control; B: Treated by YJ1; a: ascospore; b: germ tube.

\subsection{YJ1 Colonization}

In this study, we obtained the marker strain that could grow stably on Gause's medium No.1 which added with 500 $\mu \mathrm{g} / \mathrm{mL}$ streptomycin. The physiological characteristics of marker strain were consistent with the original strain, and it also had antagonistic effects against S. sclerotiorum. 
We also found the strain YJ1 could colonize stably in rhizosphere soil and roots of rape for a long time (Figure 4). After applying soil drench with YJ1, we detected the number of YJ1 in rhizosphere soil and roots of rape at different days. It was $4.69 \times 10^{5} \mathrm{cfu} / \mathrm{g}$ at 15 day and $1.308 \times 10^{6} \mathrm{cfu} / \mathrm{g}$ at 30 day in rhizosphere soil. At 75 day the quantity of YJ1 ranged to $9.12 \times 10^{5} \mathrm{cfu} / \mathrm{g}$. The change was relatively stable. In rape roots, from the 15 day to 45 day, the quantity of YJ1 firstly increased to $2.312 \times 10^{5} \mathrm{cfu} / \mathrm{g}$; and then declined to $1.87 \times 10^{4} \mathrm{cfu} / \mathrm{g}$ at 60 day. It had a little increasing at 75 day and the quantity was about $9.8 \times 10^{4} \mathrm{cfu} / \mathrm{g}$. Those results showed that YJ1 colonization was different in rhizosphere soil and roots of rape.

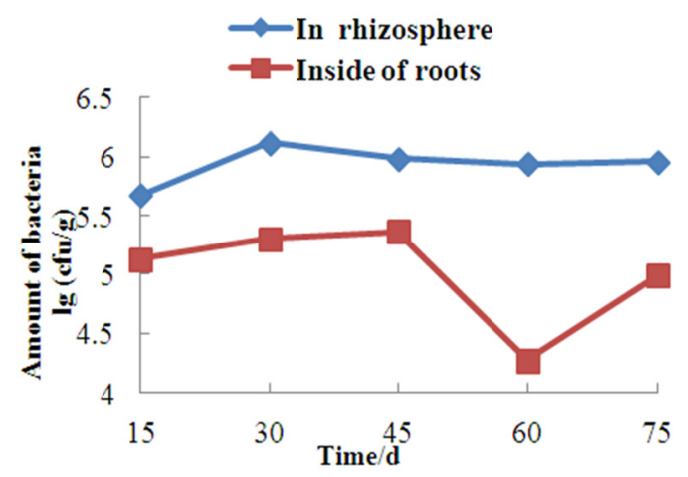

Figure 4 Colonization of strainYJ1 in rhizosphere soil and roots of oilseed rape

\subsection{Effects of YJ1 on Symptom Development}

The leaves were first sprayed with YJ1 fermentation liquid, and then inoculated with S. sclerotiorum. We found YJ1 had an obvious effect on symptom development. The lesion was smaller and slighter compared to untreated leaves (Figure 5). The inhibition rate reached to $79.91 \%$ (Table 5).

Table 5. The effects of YJ1 on lesion size in greenhouse experiment

\begin{tabular}{ccc}
\hline Treatment & $\begin{array}{c}\text { Average lesion } \\
\text { diameter }(\mathrm{mm})\end{array}$ & Control effect (\%) \\
\hline Control & $22.4 \pm 0.41 \mathrm{a}$ & - \\
YJ1 & $4.5 \pm 0.04 \mathrm{~b}$ & $79.91 \pm 0.55$
\end{tabular}

Note: Values in the table are mean \pm SD. Different letters in the same column represent significant differences $(\mathrm{P}<0.01)$.

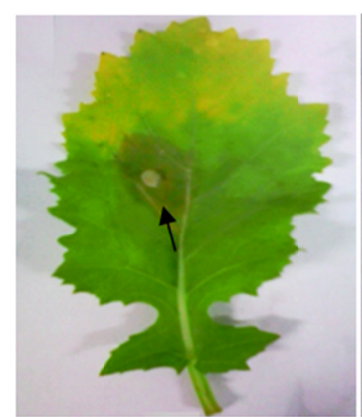

A

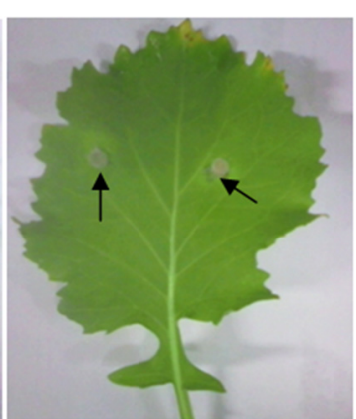

B

Figure 5. Inhibitory effect of YJ1 on S. sclerotiorum on rapeseed leaves

A: Control; B: Treated by YJ1. Where arrow point at is mycelia of S. sclerotiorum. 


\section{Discussion}

In this study, we found that the mycelial growth of S. sclerotiorum and formation of sclerotia were inhibited extremely by Streptomyces felleus YJ1. Sclerotia germination was also restricted. The results were consistent with the reports by Zhu, et al. (2008) and Han, et al. (2011). In addition, apothecia formation and the germination of ascospores were also restricted obviously by YJ1. Sclerotium is an important survival structure, which can survive in the summer and winter or other extreme circumstances (Huang \& Kozub, 1989). In favorable condition, sclerotium can germinate to form hyphae directly and also can produce apothecia to release a lot of ascospores (Abawi \& Grogan, 1979). Therefore, sclerotium becomes a very important part in the life cycle of S. sclerotiorum. According to this, delay or inhibition of sclerotia germination can reduce the sources of primary infection, and the speed of disease epidemics will also be retarded partly. If ascospores germination was restricted, the sources of primary would be reduced largely. Therefore, biocontrol of the strain YJ1 against $S$. sclerotiorum exhibited a potential application.

Using antagonistic microorganisms to control plant diseases, the key is to determine whether the strains can colonize in the target crops or their surrounding environment and whether the strains can act antagonistic function or not (Lian et al., 2011; Chen et al., 2011; Zhu et al., 2005). It is necessary to make sure the colonization ability of the strains as well as their antagonistic effects after colonization (Guo, 1998). Many scholars such as Yuan \& Zhou (2006) and Guo, et al. (1996) considered these as important indicators to evaluate the antagonistic strains. In this study, the strain YJ1 could colonize stably in rhizosphere and roots of rape. The quantity was large and the strain could frequently keep for a long period. The similar results were obtained by Guo (2005), and Wang, et al. (2002). Our results indicated that Streptomyces felleus YJ1 had a good prospect as a biological control strain.

In summary, Streptomyces felleus YJ1 had strong antagonism against Sclerotinia sclerotiorum and good potential for colonization. It is apparent that Streptomyces felleus YJ1 has great potential to control oilseed rape sclerotinia stem rot caused by S. sclerotiorum.

\section{Acknowledgements}

The work was supported by "Commonweal Specialized Research Fund of Chinese Agriculture" (201103016) and research of technical solutions about S. sclerotiorum.

\section{References}

Abawi, G. S., \& Grogan, R. G. (1979). Epidemiology of diseases caused by Sclerotinia species. Phytopathology, 69, 899-904. http://dx.doi.org/10.1094/Phyto-69-899

Abdullah, M. T., Ali, N. Y., \& Suleman, P. (2008). Biological control of Sclerotinia sclerotiorum (Lib.) de Bary with Trichoderma harzianum and Bacillus amyloliquefaciens. Crop Protection, 27, 1354-1359. http://dx.doi.org/10.1016/j.cropro.2008.05.007

Adams, P. B., \& Ayers, W. A. (1979). Ecology of Sclerotinia species. Phytopathology, 69, 896-898. http://dx.doi.org/10.1094/Phyto-69-896

Bae, Y. S., \& Knudsen, G. R. (2007). Effect of sclerotial distribution pattern of Sclerotinia sclerotiorum on biocontrol efficacy of Trichoderma harzianum. Appl. Soil Ecol., 35, 21-24. http://dx.doi.org/10.1016/j.apsoil.2006.05.014

Chen, H. B., Kang, Y., \& Fang, M. (2011). Colonization of Two Strains Endophytic Actinomycetes in Maize and Their Control Effect on Diseases. Southwest China Journal of Agricultural Sciences, 24(1), 117-19.

Clardy, J., Fischback, M. A., \& Walsh, C. T. (2006). New antibiotic from bacterial natural products. Nature Biotech, 24, 1541-1550. http://dx.doi.org/10.1038/nbt1266

Demoz, B. T., \& Korsten, L. (2006). Bacillus subtilis attachment, colonization, and survival on avocado flowers and its mode of action on stem-end rot pathogens. Biological Control, 37, 68-74. http://dx.doi.org/10.1016/j.biocontrol.2005.11.010

Fernando, W. G. D., Nakkeeran, S., Zhang, Y., \& Savchuk, S. (2007). Biological control of Sclerotinia sclerotiorum (Lib.) de Bary by Pseudomonas and Bacillus species on canola petals. Crop Protection, 26, 100-107. http://dx.doi.org/10.1016/j.cropro.2006.04.007

Fróes, A., Macrae, A., \& Rosa, J. (2012). Selection of a Streptomyces strain able to produce cell wall degrading enzymes and active against Sclerotinia sclerotiorum. The Journal of Microbiology, 50(5), 798-806. http://dx.doi.org/10.1007/s12275-012-2060-2

Guo, J. H. (1998). Biological control of ralstonia solanacearum. Dissertation, Nanjing Agricultural University. 
Guo, J. H., Wang, Y. J., \& Li, J. (1996). Screen of biocontrol bacteria of plant wilt by inhibiting zones and root-colonization capacity. Acta Phytopathologica Sinica, 26(1), 49-54.

Guo, X. F., Zong, Z. F., \& Yang, H. J. (2005). Resistance Tag of 6 strains of Actinomyces and Their Colonized Ability in Plants. Acta Agriculturae Boreali-Occidentalis Sinica, 14(2), 69-73.

Han, L. R., Sun, P. P., \& Zhang, N. (2011). Isolation and screening of biocontrol actinomyces against Sclerotinia sclerotiorum. Journal of Anhui Agricultural Science, 39(5), 2668-2670.

Hegedus, D. D., \& Rimmer, S. R. (2005). Sclerotinia sclerotiorum: When "to be or not to be" a pathogen. FEMS Microbiology Letters, 251, 177-184. http://dx.doi.org/10.1016/j.femsle.2005.07.040

Huang, H. C., \& Kozub, G. C. (1989). A simple method for production of apothecia from sclerotia of Sclerotinia sclerotiorum. Plant Protection Bulletin, 31, 333-345.

Huang, H. C., Bremer, E., Hynes, R. K., \& Erickson, R. S. (2000). Foliar application of fungal biocontrol agents for the control of white mold of dry bean caused by Sclerotinia sclerotiorum. Biol Control, 18, 270-276. http://dx.doi.org/10.1006/bcon.2000.0829

Lian, L. L., Xie, L. Y., \& Chen, J. M. (2011). Colonization of biocontrol strain EN5 and its effects on rhizosphere soil microbial communities. Plant Protection, 37(2), 35. http://dx.doi.org/10.3969/j.issn.0529-1542.2011.02.006

Mueller, D. S., Dorrance, A. E., \& Derksen, R. C. (2002). Efficacy of fungicides on Sclerotinia sclerotiorum and their potential for control of sclerotinia stem rot on soybean. Plant Disease, 86, 26-31. http://dx.doi.org/10.1094/PDIS.2002.86.1.26

Subbarao, K. V. (1998). Progress toward integrated management of lettuce drop. Plant Disease, 82, 1068-1078. http://dx.doi.org/10.1094/PDIS.1998.82.10.1068

Wang, Z. W., Li, X. Z., Liu, Y. L., \& Tian, H. T. (2002). Colonization and population dynamics of Bacillus subtilis B501 in the rhizosphere of strawberry. Acta Phytopathologica Sinica, 33(2), 188-189.

Yan, L. Y., Zhou, L. C., Tan, \& Y. J. (2005). Isolation and identification of biocontrol bacteria from rhizosphere of rapeseed. Chinese journal of oil sciences, 27(2), 55-61.

Yao, J. (2010). Study on the Biocontrol of Sclerotinia sclerotiorum by Antagonistic Actinomycetes. Dissertation, Sichuan Agricultural University.

Yuan, S. Z., \& Zhou, M. G. (2006). Screening and root colonization of biocontrol agents against Phytophthora capsici. Journal of Yangzhou University (Agricultural and Life Science edition), 27(4), 93-97.

Yuan, W. M., Crawford, D. L. (1995). Characterization of Streptomyces lydicus WYEC108 as a potential biocontrol agent against fungal root and seed rots. Appl. Environ. Microbiol., 61, 3119-3128.

Zhu, Y. J., Liu, B., \& Lin, K. M. (2005). Effects of different medium formula on preservation, control efficacy and soil fixability of the biocontrol agent ANTI-8098A (Bacillus cereus). Plant Protection, 31(4), 58-61.

Zhu, Z. B., Lv, W. J., Ji, Z. L., \& Tong, Y. H. (2008). Isolation of biocontrol actinomycetes in soil and their inhibitory effects on Sclerotinia sclerotiorum. Xiandai Nongye Keji, 12, 106-108.

\section{Copyrights}

Copyright for this article is retained by the author(s), with first publication rights granted to the journal.

This is an open-access article distributed under the terms and conditions of the Creative Commons Attribution license (http://creativecommons.org/licenses/by/3.0/). 